\title{
Rochas Ricas em Turmalina da Formação Morro da Pedra Preta: Relações com os Turmalinitos Portadores de Ouro do Grupo Serra do Itaberaba, SP
}

\author{
Gianna Maria Garda' (giagarda@usp.br), Paulo Beljavskis', Marcos de Souza Mansueto² \\ 'Departamento de Geologia Sedimentar e Ambiental - Instituto de Geociências - USP \\ R. do Lago 562, CEP 05508-080, São Paulo, SP, BRA \\ ${ }^{2}$ Departamento de Mineralogia e Geotectônica - Instituto de Geociências - USP, São Paulo, SP, BRA
}

Recebido em 16 de novembro de 2005; aceito em 02 de fevereiro de 2006

Palavras-chave: Grupo Serra do Itaberaba, Formação Morro da Pedra Preta, turmalinitos, turmalina.

\section{RESUMO}

A turmalina é um mineral comum no Grupo Serra do Itaberaba, particularmente na Formação Morro da Pedra Preta. Dentre as rochas ricas em turmalina, destacam-se: turmalinitos, metatufos básicos, metavulcanoclásticas intermediárias a ácidas, metapelitos e veios de quartzo. A presença de ouro disseminado em turmalinito do prospecto Tapera Grande estimulou a investigação da relação entre os ambientes de formação dos turmalinitos e as mineralizações do Grupo Serra do Itaberaba. A investigação é ampliada neste trabalho, incluindo metatufos básicos, metavulcanoclásticas intermediárias a ácidas e metapelitos que, além de conter turmalina, apresentam indícios de silicificação, carbonatização, potassificação, cloritização e sulfetização. A química da turmalina revelou que mesmo nas porções mais proximais ao centro exalativo, a razão fluido/rocha foi baixa, pois a turmalina preserva muitas das características da rocha hospedeira do que propriamente as dos fluidos ricos em boro que a geraram. Os fluidos, de origem hidrotermal-metamórfica, promoveram a redistribuição de ouro sin-sedimentar ou singenético; entretanto, sua composição (aquo-carbônica, baixa salinidade), não favoreceu a formação de depósitos de sulfetos maciços.

Keywords: Serra do Itaberaba Group, Morro da Pedra Preta Formation, tourmalinites, tourmaline.

\section{ABSTRACT}

Tourmaline is a common mineral in the Serra do Itaberaba Group (Guarulhos-Brazil), especially in its basal, volcanicsedimentary sequence, the Morro da Pedra Preta Formation. Tourmalinites, basic metatuffs, intermediate to acid metavolcaniclastic rocks, metapelites and quartz veins are among the tourmaline-rich rocks. The presence of gold disseminated in a tourmalinite of the Tapera Grande prospect led to the investigation of the relation between the environments of tourmalinite genesis and mineralizations in the Serra do Itaberaba Group. The investigation was extended to tourmaline-rich basic metatuffs, intermediate to acid metavolcaniclastic rocks, and metapelites that also show some silicification, carbonatization, potassification, chloritization and sulfidation. The tourmaline chemistry showed that even in the regions proximal to the exhalative center, the fluid/rock ratio is low because the tourmaline preserves most of the host rock's characteristics rather than those of the boron-rich fluids themselves. Such hydrothermal-metamorphic fluids promoted the redistribution of synsedimentary or syngenetic gold. The composition (aqueous-carbonic, low-salinity) of these fluids, however, did not favor the formation of massive sulfide deposits. 


\section{INTRODUÇÃO}

Diversos autores alertaram da importância da turmalina como indicador petrogenético, pela sua ampla ocorrência como mineral autigênico em rochas sedimentares e metamórficas (e.g. Henry e Guidotti, 1985; Plimer, 1986, 1988; Yavuz, 1997). Na prospecção mineral, a turmalina rica em Mg associa-se a depósitos de sulfetos maciços e exalitos (Plimer, 1986, 1987, 1988; Slack, 1982, 1996; Slack et al., 1984; Taylor e Slack, 1984; Willner, 1992), ao passo que a rica em Fe associa-se a rochas plutônicas (Taylor e Slack, 1984) e exalitos (Plimer, 1983).

A turmalina é um mineral comum no Grupo Serra do Itaberaba, particularmente na seqüência basal vulcanosedimentar denominada Formação Morro da Pedra Preta (Juliani, 1993), que foi explorada para ouro nos séculos XVIe XVII.

A microscopia eletrônica de varredura revelou a presença de ouro disseminado em turmalinitos e rochas associadas no prospecto Tapera Grande (Beljavskis, Garda e Sayeg, 1999), o que levou Beljavskis et al. (2005) a investigar implicações metalogenéticas da turmalina dos turmalinitos vulcanogênicos da Formação Morro da Pedra Preta.

As rochas associadas aos turmalinitos são, em geral, ricas em turmalina, indicando uma possível relação genética entre a turmalina dessas rochas e aquela dos turmalinitos.

\section{CONTEXTO GEOLÓGICO}

O Grupo Serra do Itaberaba constitui uma seqüência vulcano-sedimentar metamorfizada cuja distribuição é limitada pelas zonas de cisalhamento de Itu-Jundiuvira, Taxaquara e do Rio Jaguari (Figura 1). O Grupo é composto por três formações, denominadas Morro da Pedra Preta, Nhanguçu e Pirucaia (Juliani, 1993; Juliani e Beljavskis, 1995).

A unidade basal (Formação Morro da Pedra Preta) é formada predominantemente por metabasaltos (N-MORB), metabrechas, metatufos e rochas metavulcanoclásticas de composições básica, intermediária e ácida. Xistos de granulação fina a grossa, comumente com leitos de metachert e grafitosos intercalados, são geralmente formados por biotita, granada, muscovita, estaurolita e pouco quartzo, podendo conter, ainda, cianita, sillimanita, andalusita, cordierita, grafita, óxidos de ferro e manganês, e sulfetos. Subordinadamente ocorrem pequenas intrusões de andesito, dacito, riodacito e riolito metamorfizadas, rochas calciossilicáticas, formações ferríferas de facies silicato e óxido (com magnetita ou hematita) e marunditos.

A Formação Nhanguçu, formada em ambiente de retroarco, recobre a anterior e é formada por xistos ferromanganesíferos, por vezes calciossilicáticos, com lentes de anfibolitos, rochas calciossilicáticas e mármores. Sobre os xistos ferro-manganesíferos ocorrem xistos finos, bandados a laminados, com lentes de quartzitos, formados por muscovita, clorita, andalusita e magnetita. A Formação Pirucaia, depositada em ambiente litorâneo, corresponde às facies marginais da Formação Nhanguçu e é constituída quase que exclusivamente por xistos quartzosos e quartzitos, comumente com zircão detrítico.

O Grupo Serra do Itaberaba foi afetado por dois eventos metamórficos regionais. O primeiro deles, do tipo barroviano, ocorreu no Mesoproterozóico, indo da facies xisto verde transicional para anfibolito $\left(490^{\circ} \mathrm{C}, 4 \mathrm{kbar}\right)$ na parte $\mathrm{SW}$ até a facies anfibolito $\left(650^{\circ} \mathrm{C}, 7 \mathrm{kbar}\right)$ na extremidade NW. O segundo evento foi de baixa pressão e ocorreu no Neoproterozóico, sendo que o grau metamórfico variou entre xisto verde $\left(500^{\circ} \mathrm{C}, 4 \mathrm{kbar}\right)$ e anfibolito $\left(580^{\circ} \mathrm{C}, 4,7 \mathrm{kbar}\right)$. Houve, ainda, retrometamorfismo em facies xisto verde que afetou a maioria das rochas da área (Juliani, Pérez-Aguilar e Martin, 1997; Juliani et al., 2000).

\section{ROCHAS RICAS EM TURMALINA DA FORMAÇÃO MORRO DA PEDRA PRETA}

Na Formação Morro da Pedra Preta ocorrem desde rochas ricas em turmalina (até 10\%) até turmalinitos. Beljavskis (2003) e Beljavskis et al. (2005) caracterizaram os turmalinitos que ocorrem no prospecto Tapera Grande como proximais e proximais a intermediários (Figura 2). Estão associados a metatufos básicos, metavulcanoclásticas e metatufos intermediários a ácidos e metapelitos. Um turmalinito caracterizado como distal, associado a rochas alteradas por evento hidrotermal anterior ao metamorfismo (Juliani, 1993), ocorre a NNE de Tapera Grande (ponto SI-1611 da Figura 1b). Os turmalinitos apresentam texturas sedimentares preservadas, como a alternância de finas camadas de quartzo e de turmalina e clastos rip-up (Figuras 3a a 3c).

Dentre as rochas ricas em turmalina, destacam-se neste trabalho metatufos básicos, metavulcanoclásticas intermediárias a ácidas e metapelitos, que podem apresentar indícios de silicificação, carbonatização, potassificação, cloritização e sulfetização.

\section{Metatufos básicos ricos em turmalina}

Os metatufos básicos ricos em turmalina são biotita hornblenda xistos, de coloração cinza-esverdeada a verde escura e de granulação fina a média, com estrutura bandada ou xistosa. Os minerais essenciais que os compõem são anfibólio, plagioclásio, biotita e quartzo. As amostras deste estudo provêm dos seguintes trechos de testemunhos das sondagens SRT1 e SRT2 (Figura 2): $38,60 \mathrm{~m}$ a $38,64 \mathrm{~m}$ (SRT1-30); 27,00 m a 27,50 m (SRT2-42), e 54,60 m a $54,76 \mathrm{~m}$ (SRT2-97). 


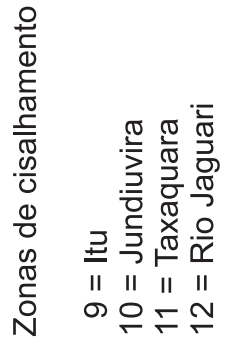

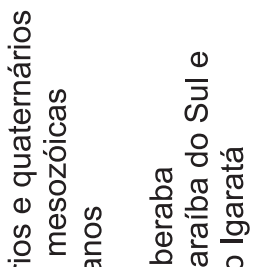

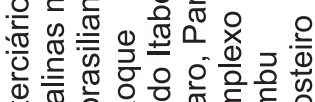

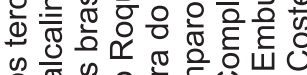

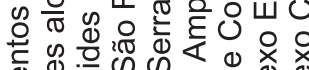

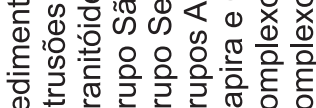

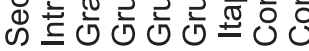

॥ I| || || || ||

$-\sim m \forall 10 \quad \wedge \infty$

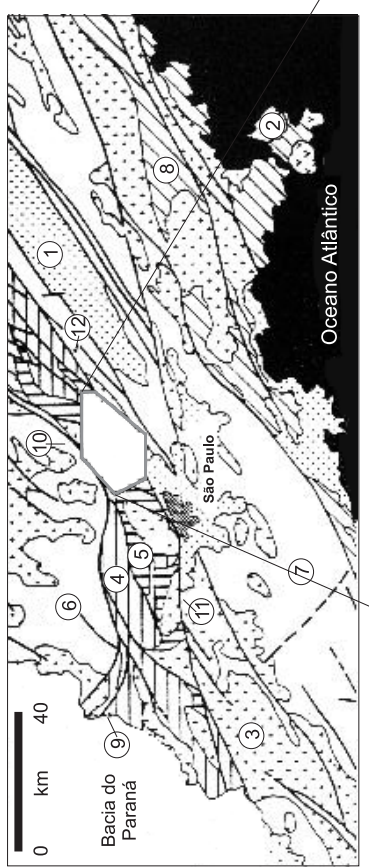

(ฮ)

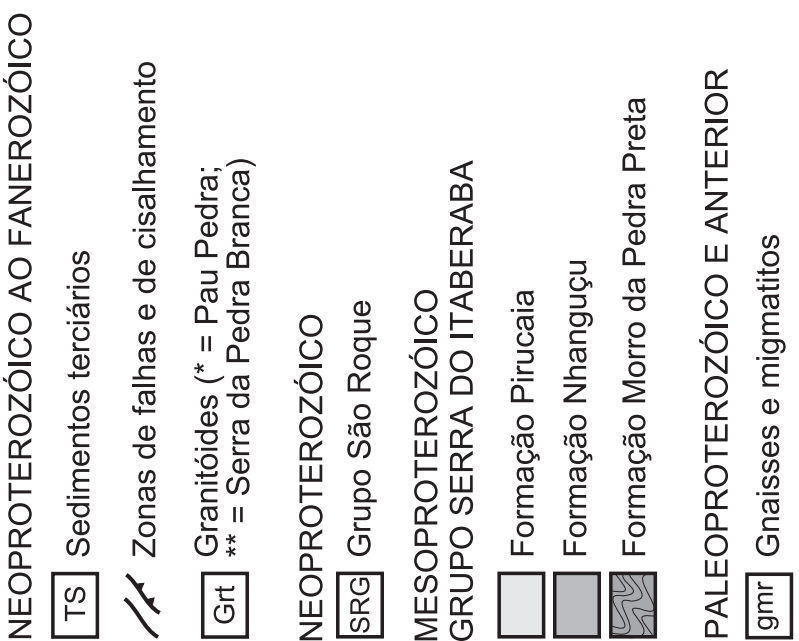

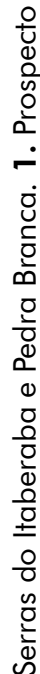

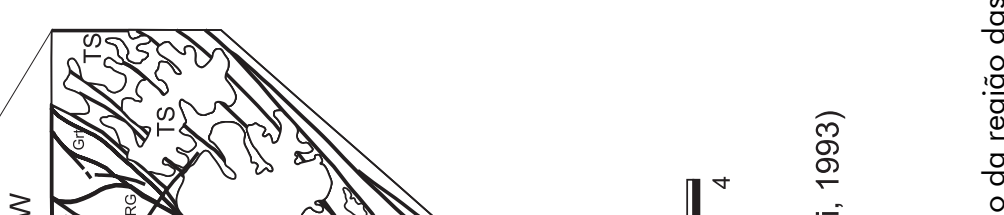

3

छे

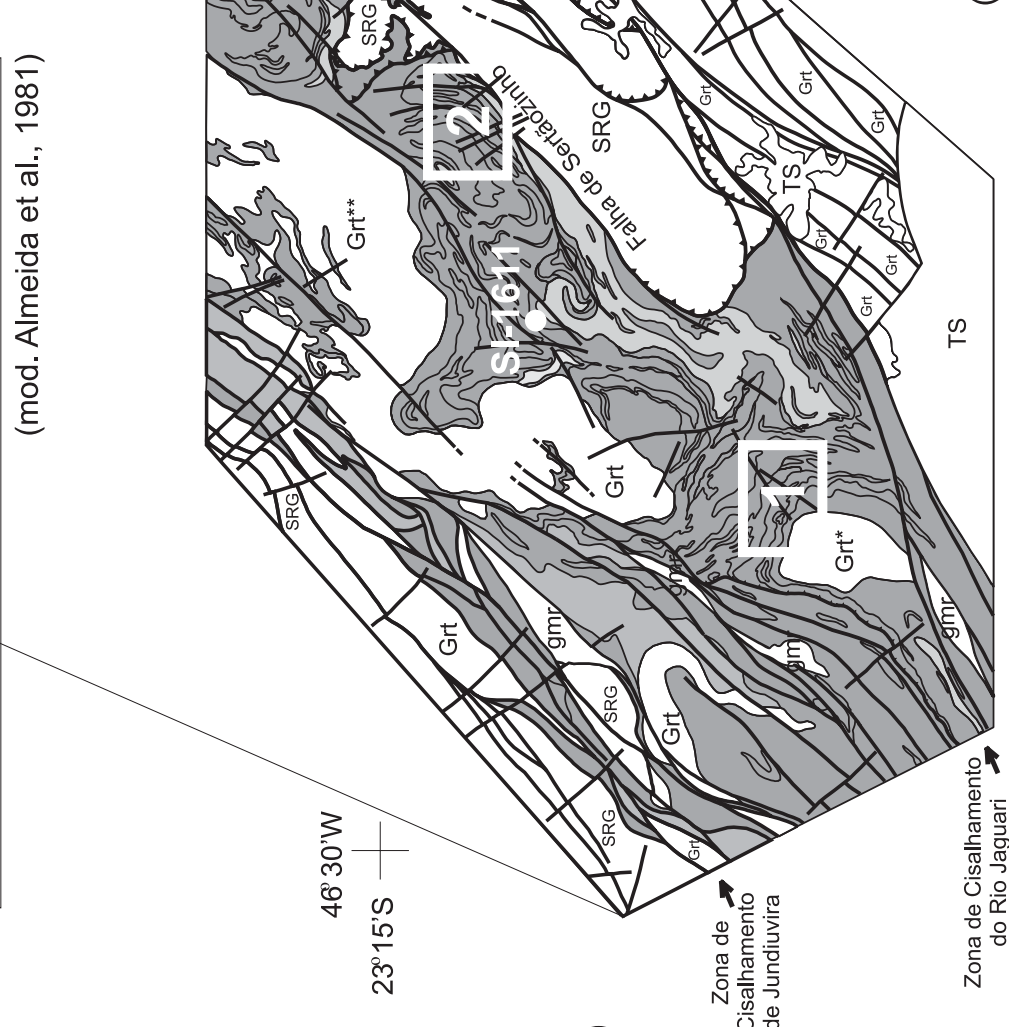

(2)
응

?음

응

送

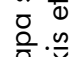

$\sum^{\frac{0}{2}} \frac{\frac{\pi}{v}}{\frac{0}{5}}$

으.흔

రํํㅇ $\frac{\emptyset}{0}$

힐 $\frac{\overline{0}}{\frac{5}{2}}$

호

응

을 है

은

过

응 둔

을

힝

$\cdot \frac{0}{0} 0$

व

은

穵

ن 웜

ธิ 흔

50

혼 임 


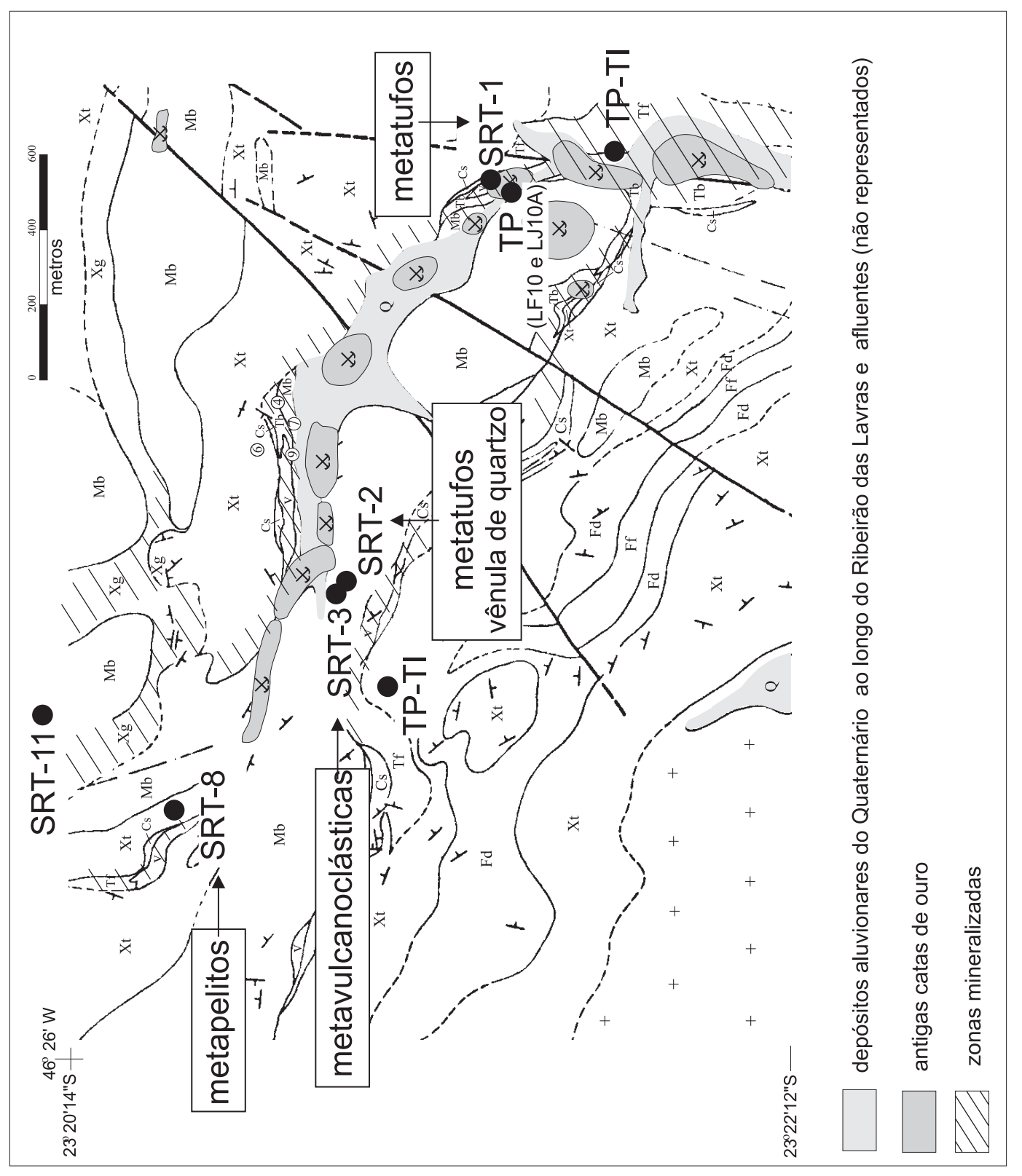

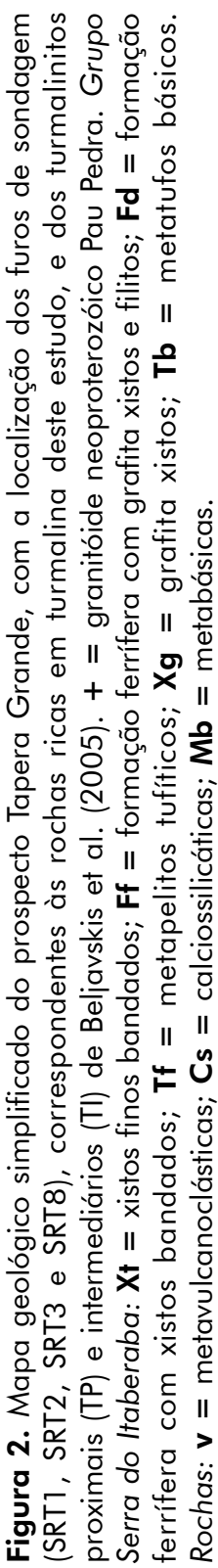



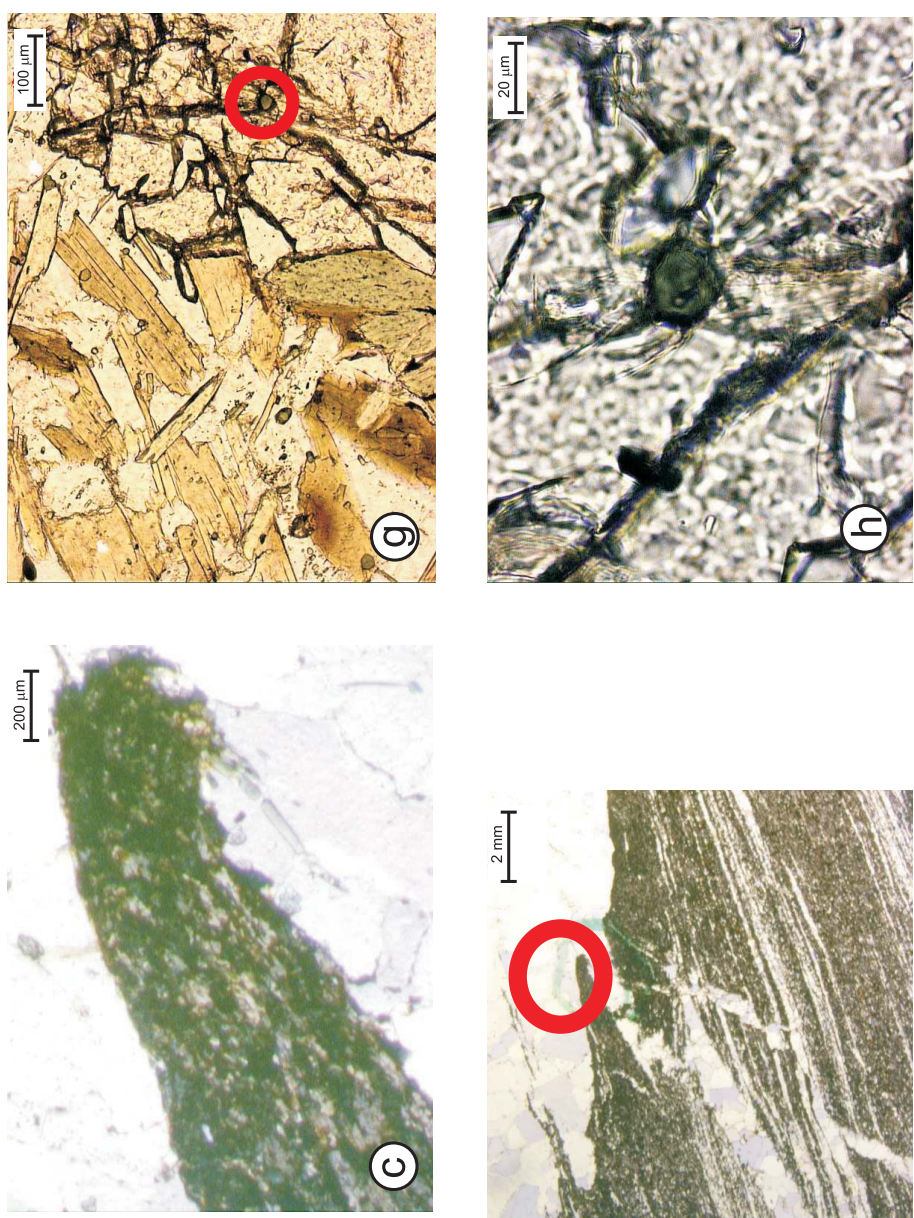

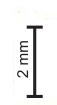

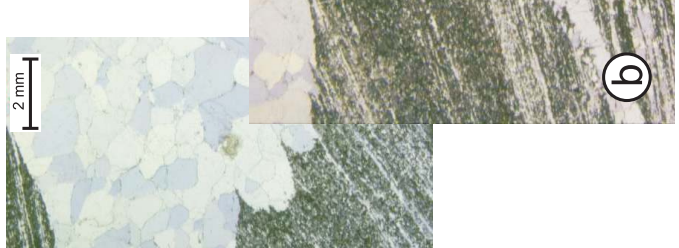

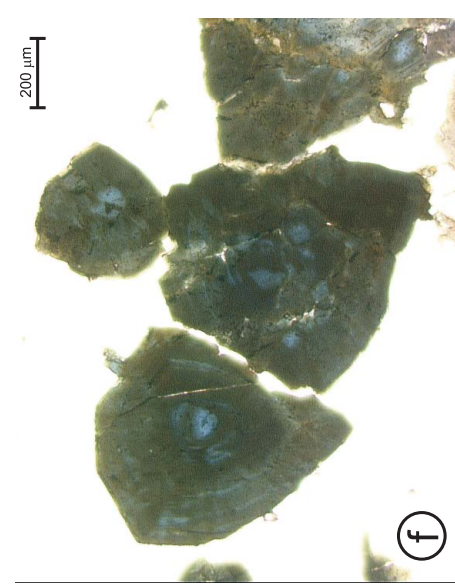
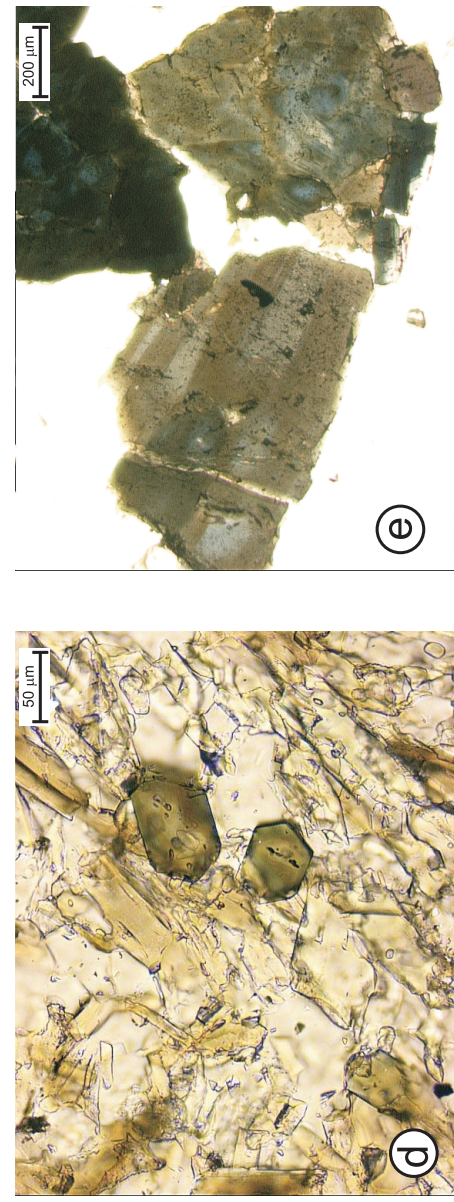

웅울 웅 움

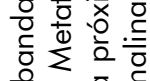

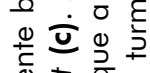

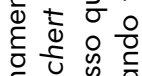

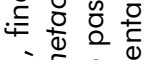

उे ह 웛

층 흐믐

¿

온 옿

ठ ํำ

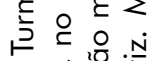

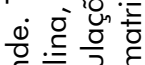

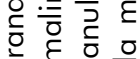

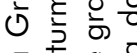

일 동 응

응 ․ㅗㅇ

은 는 흥 응

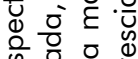

웡 은 은

흐응응

응 으응

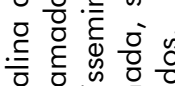

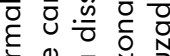

능엉

ह

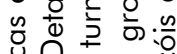

는 4 .

응 $\Phi^{Z}$

บ 0 눈

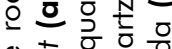

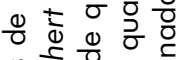

은 원은 은

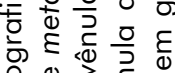

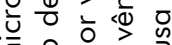

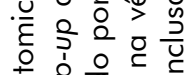

눈 은음 $\frac{1}{0}$

m 온 $\frac{t}{0}$ 음ㅇ

힌 은

(ช) 
Anfibólio de granulação média predomina nas três amostras. Os minerais opacos de granulação muito fina (ilmenita ou titanomagnetita) e envoltos por titanita aparecem alinhados ou "salpicando" os demais minerais. Pirita, pirrotita e calcopirita, de granulação mais grossa e menos freqüentes que os minerais opacos finos, aparecem dispersos.

Há indícios de potassificação, silicificação e carbonatização incipientes na seção SRT1-30. Biotita e anfibólio formam uma trama fechada, em meio à qual ocorrem pequenos bolsões de quartzo. A turmalina encontra-se em uma porção da seção onde predomina anfibólio. Apresenta bordas difusas e concentra-se em "manchas" escuras; é zonada, mas o zoneamento é bastante irregular. A turmalina entremeia-se ao anfibólio.

$\mathrm{Na}$ amostra SRT2-42, a biotita concentra-se em faixas, onde encontra-se turmalina de granulação muito fina a fina. É invariavelmente zonada. A seção SRT2-42 apresenta indícios de carbonatização e silicificação.

A seção SRT2-97 corresponde a um anfibólio biotita xisto carbonatizado e silicificado, contendo três tipos de turmalina. $\mathrm{O}$ primeiro tipo apresenta pleocroismo de verde a marrom; a turmalina é fina a muito fina, podendo conter inclusões, e ocorre disseminada na rocha (Figura 3d). O segundo é representado por cristais incompletos de turmalina, mais grossos, sobrecrescidos à turmalina do primeiro tipo (Figura 3e). O terceiro tipo ocorre nas proximidades de uma vênula de quartzo e caracteriza-se pela granulação grossa e por ser poiquilítico. No contato da vênula com a rocha e dentro da vênula, a turmalina tem cor e pleocroismo mais intensos, variando de azul escuro a marrom (Figura 3f). É zonada, geralmente apresentando borda mais escura que o núcleo. Próximo à vênula de quartzo ocorre um nível com carbonatos.

\section{Metavulcanoclásticas intermediárias a ácidas ricas em turmalina}

As amostras de metavulcanoclásticas ricas em turmalina provêm dos trechos de 50,50 m a 50,80 m (SRT3-92) e de $60,60 \mathrm{~m}$ a $61,10 \mathrm{~m}$ (SRT3-112) do furo de sondagem SRT3 (Figura 2). Nesse furo, são freqüentes intercalações com metatufos básicos e rochas calciossilicáticas.

As metavulcanoclásticas intermediárias a ácidas incluem hornblenda gnaisses tonalíticos, quartzo dioritos gnáissicos, biotita-hornblenda gnaisses e hornblendabiotita gnaisses, que não apresentam mais texturas primárias preservadas. A foliação metamórfica, por sua vez, foi transposta e submetida a deformações mais tardias (Juliani, 1993). Em geral, as vulcanoclásticas constituem corpos lenticulares situados nos topos de derrames básicos ou pequenas lentes intercaladas em xistos. São maciças ou bandadas a laminadas, quando anfibólio e plagioclásio concentram-se preferencialmente em leitos. Esses minerais também podem formar agregados lenticulares. Há sempre predomínio de feldspato sobre o anfibólio e a granulação é fina a média.

A amostra SRT-3-92 corresponde a um quartzo diorito gnáissico, em que se alternam faixas mais ricas em quartzo (de granulação mais grossa) e faixas com quartzo e feldspato. A turmalina constitui uma banda centimétrica rica em opacos. Predominam cristais com pleocroismo variando desde marrom claro a marrom escuro; subordinadamente ocorre turmalina azul com bordas castanhas. Os opacos, próximo a essa banda, preenchem espaços entre grãos de quartzo, oligoclásio e microclínio.

A amostra SRT-3-112 é um hornblenda gnaisse tonalítico fracamente silicificado e carbonatizado, em contato com rochas calciossilicáticas. É laminada e, ao microscópio, observa-se que os níveis máficos são formados por hornblenda, biotita, minerais opacos e turmalina. A turmalina apresenta núcleos azulados e bordas castanhas, podendo concentrar-se em níveis que seguem a deformação das demais camadas. Os minerais opacos entremeiam-se com os cristais de turmalina. Os níveis félsicos são formados por plagioclásio de granulação mais grossa que a dos demais minerais. Apresenta-se coalhado de inclusões muito finas de provável mica. Quartzo apresenta abundantes inclusões fluidas.

\section{Metapelitos ricos em turmalina}

É freqüente a ocorrência de turmalina na seqüência de metapelitos do furo de sondagem SRT8 (Figura 2), em especial no intervalo entre 45 e $52 \mathrm{~m}$, onde também se observam intercalações de metatufo básico. As amostras estudadas correspondem aos trechos de 47,85 $\mathrm{m}$ a 48,35 m (SRT8-77) e de 48,85 m a 49,35 m (SRT8-79).

Os metapelitos são finos e constituídos predominantemente por quartzo e biotita, esta podendo ocorrer em proporções variadas ao longo do perfil de sondagem. Clorita, sericita/muscovita, granada e estaurolita poiquiloblástica são minerais que caracterizam o metamorfismo e a alteração dos metapelitos.

A amostra SRT8-77 é um clorita biotita quartzo xisto com granada, apresentando faixas centimétricas cloritizadas onde o quartzo aparece com granulação mais grossa. Segundo Juliani (1993), a clorita deriva da biotita por retrometamorfismo sin-cataclástico ou daquele ocorrido durante o desenvolvimento das clivagens de crenulação. Feldspato (raro) ocorre em alguns leitos mais quartzosos, com clorita associada.

Turmalina é em geral verde claro, muito fina e encontrase dispersa na rocha ou concentrada em finas bandas. 
A granada da amostra SRT8-77, que se concentra em uma camada fina, é de granulação sempre mais grossa que os demais minerais e pode incluir turmalina (Figuras $3 \mathrm{~g}$ e $3 h$ ). Por sua vez, turmalina muito fina também pode se concentrar ao redor da granada (na zona de sombra de pressão), o que indica que a formação de turmalina é anterior à da granada.

A amostra SRT8-79 é de estaurolita biotita quartzo xisto. A seção apresenta uma faixa centimétrica, composta por quartzo de granulação grossa, dobrada. Na parte interna da dobra, próximo ao ápice, concentra-se biotita bem mais grossa do que a que predomina na seção. A biotita dispõe-se nos planos que delineiam a crenulação. Os porfiroclastos de estaurolita são poiquilíticos e também aparecem deformados. Feldspato aparece de forma irregular na seção.

A turmalina da SRT8-79 é muito fina, esverdeada, e está disseminada. Quando um pouco maior, é possível observar um zoneamento de cor, de tons mais e menos escuros de verde.

\section{QUIMISMO DA TURMALINA}

A química mineral foi realizada por meio da microssonda eletrônica JEOL Superprobe, modelo JXA-8600, do Laboratório de Microssonda Eletrônica do Instituto de Geociências da Universidade de São Paulo. As condições de operação foram: diâmetro do feixe de 1-2 $\mu \mathrm{m}$, corrente de 15 nA e tensão de aceleração de $15 \mathrm{kV}$. As seções delgadas polidas analisadas foram confeccionadas a partir de amostras de testemunhos de sondagem e foram recobertas por carbono.

O grupo da turmalina configura-se como uma série de soluções sólidas de silicatos de boro complexos, normalmente descritos pelas proporções dos membros finais constituintes e fórmula geral (e.g. Fonseca-Zang et al., 2002):

$$
\mathrm{XY}_{3} \mathrm{Z}_{6}(\mathrm{O}, \mathrm{OH})_{3}(\mathrm{OH}, \mathrm{F})\left(\mathrm{BO}_{3}\right)_{3}\left[\mathrm{~T}_{6} \mathrm{O}_{18}\right]
$$

onde:

$\mathrm{X}=\mathrm{Na}, \mathrm{Ca}, \mathrm{K}, \mathrm{Bi}$, podendo ocorrer vacância nesta posição;

$\mathrm{Y}=\mathrm{Al}, \mathrm{Li}, \mathrm{Mg}, \mathrm{Fe}^{2+}, \mathrm{Fe}^{3+}, \mathrm{Mn}^{2+}, \mathrm{Mn}^{3+}, \mathrm{Cr}, \mathrm{V}, \mathrm{Cu}$;

$\mathrm{Z}=\mathrm{Al}, \mathrm{Fe}^{3+}, \mathrm{Cr}, \mathrm{V}, \mathrm{Mg}, \mathrm{Fe}^{2+}, \mathrm{Ti}$;

$\mathrm{B}=\mathrm{B}$;

$\mathrm{T}=\mathrm{Si}, \mathrm{Al}, \mathrm{B}$.

A Tabela 1 apresenta os resultados das análises de turmalina por microssonda eletrônica. Para o cálculo da fórmula unitária adotou-se o seguinte procedimento:
1. assumem-se 3 átomos de B;

2. preenche-se a posição $\mathrm{T}$ com $\mathrm{Si}$ e $\mathrm{Al}$, até completar 6 átomos;

3. preenche-se a posição $\mathrm{Z}$ com $\mathrm{Al}$ e $\mathrm{Fe}^{3+}$, até completar 6 átomos;

4. preenche-se a posição $\mathrm{Y}$ com $\mathrm{Al}$ e Si excedentes de (2) e (3) e $\mathrm{Mg}, \mathrm{Fe}, \mathrm{Mn}, \mathrm{Cr}$, V, Ti e Li;

5. preenche-se a posição $\mathrm{X}$ com $\mathrm{Ca}$, Na e K.

Alerta-se para o fato de que o procedimento adotado pode acarretar vacância na posição $\mathrm{X}$ (vacX), uma vez que o total de átomos nessa posição não atinge 1 . O procedimento também não leva em consideração a ocupação da posição $\mathrm{Y}$ por $\mathrm{Fe}^{3+}$ e da posição $\mathrm{Z}$ por $\mathrm{Fe}^{3+}$, fazendo com que $\mathrm{Fe}^{3+}$ seja subestimado (Slack, 1996).

Para efeito de comparação, na Figura 4 são indicados os campos de composições da turmalina dos turmalinitos de Beljavskis et al. (2005). Os valores de $\mathrm{Mg} \#\left[=\mathrm{Mg} /\left(\mathrm{Mg}+\mathrm{Fe}_{\text {total }}\right)\right.$ em átomos por fórmula unitária apfu] para a turmalina dos metatufos básicos variam entre 0,5 e 0,7 , ao passo que para aquela das vulcanoclásticas intermediárias a ácidas $\mathrm{Mg} \#<0,5$. Para a turmalina dos metapelitos e da vênula de quartzo da amostra SRT2-97, $\mathrm{Mg \#}>0,7$. As composições da turmalina dos metatufos básicos são intermediárias entre a schorlita e dravita, tendendo à dravita. São intermediárias entre as composições da turmalina dos turmalinitos de Beljavskis et al. (2005).

As composições da turmalina das metavulcanoclásticas intermediárias a ácidas tendem para schorlita e posicionamse à esquerda do campo TP (Figura 4). Tanto as composições da turmalina dos metapelitos como aquelas da vênula de quartzo da amostra SRT2-97 tendem à dravita.

Os diagramas de Henry e Guidotti (1985) são bons indicadores das associações litológicas e ambientes de formação de turmalina. Apesar de não incluírem rochas como turmalinitos e metatufos básicos, dão a indicação do ambiente de formação da turmalina constituinte dessas rochas. Assim, a Figura 5a indica que a turmalina dos metatufos básicos formou-se em ambientes análogos aos dos metapelitos e metapsamitos sem minerais formados pela saturação em $\mathrm{Al}$ (campo 5) e das rochas com quartzo, com turmalina rica $\mathrm{em} \mathrm{Fe}^{3+}$, associadas a rochas calciossilicáticas e metapelitos (campo 6). O mesmo ocorre com as metavulcanoclásticas, cujas composições da turmalina equivalem às dos granitos hidrotermalizados ricos em quartzo, sendo a turmalina rica em $\mathrm{Fe}^{3+}$ (campo 3). A correspondência para os metapelitos é mais adequada (campos 4 e 5), prevendo, inclusive a existência de minerais formados pela saturação em $\mathrm{Al}$. O mesmo pode ser visto na Figura $5 b$, onde as composições da turmalina dos metapelitos equivalem àquelas dos metapelitos e metapsamitos pobres em Ca e rochas com quartzo e turmalina (campo 4). 


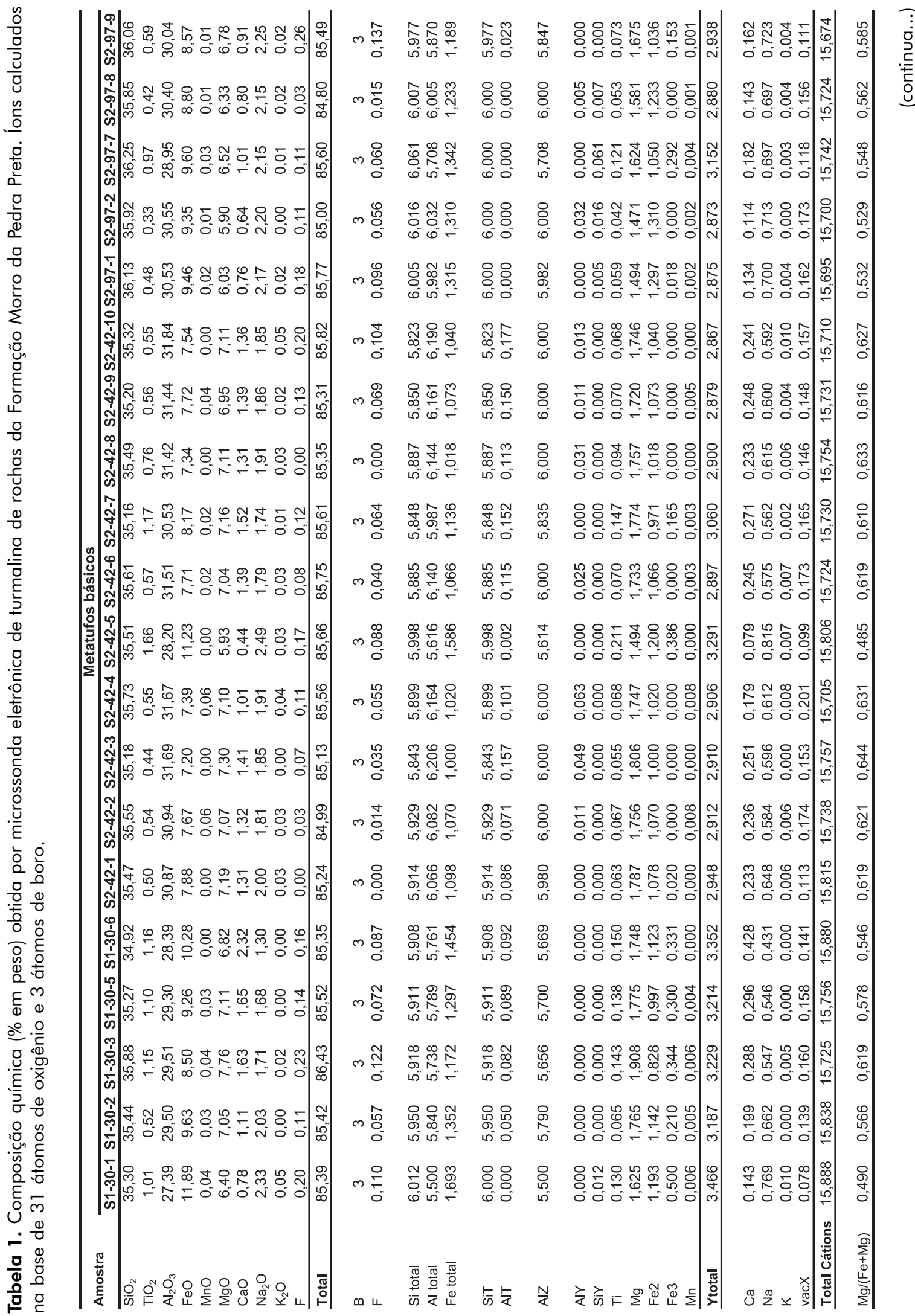




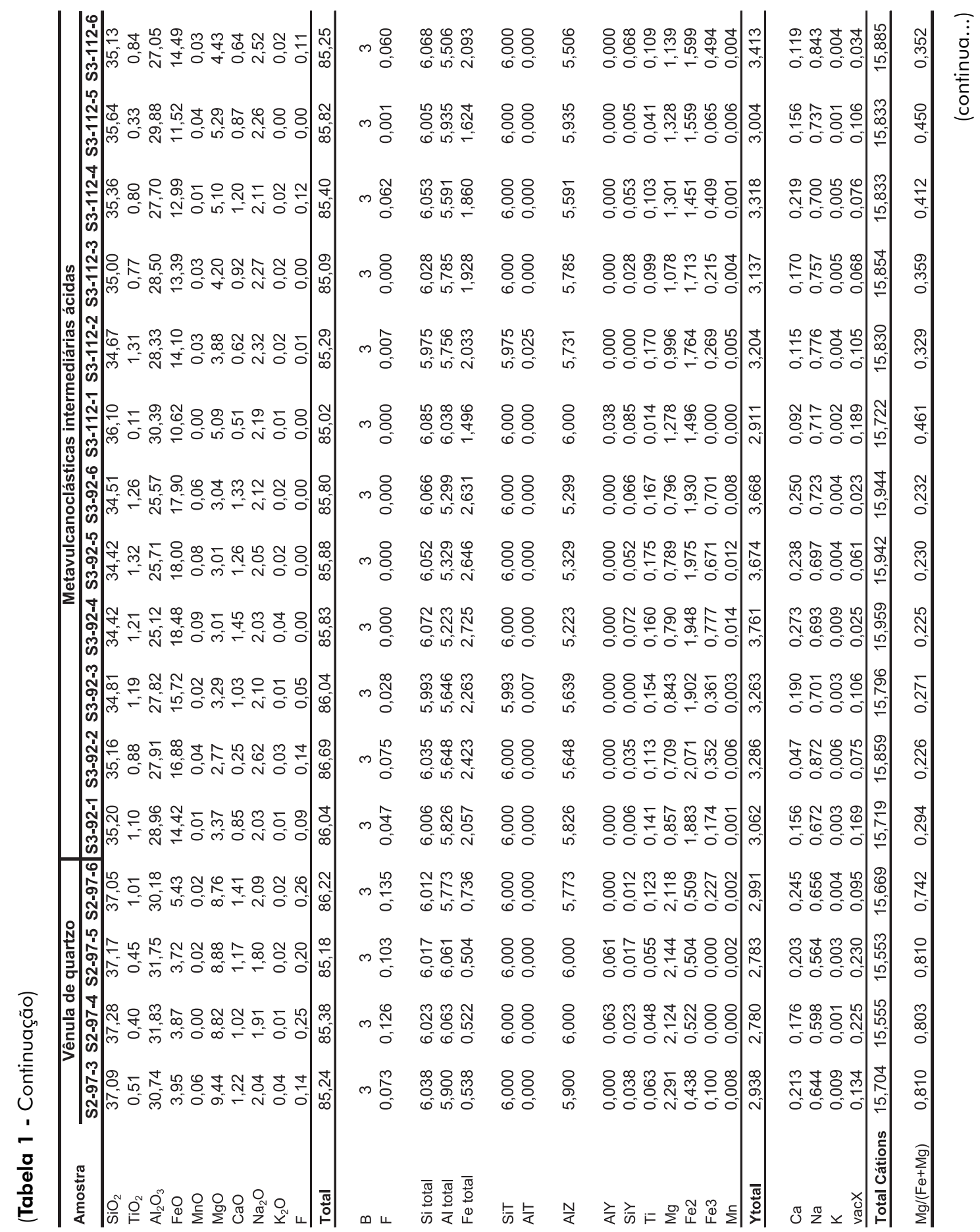




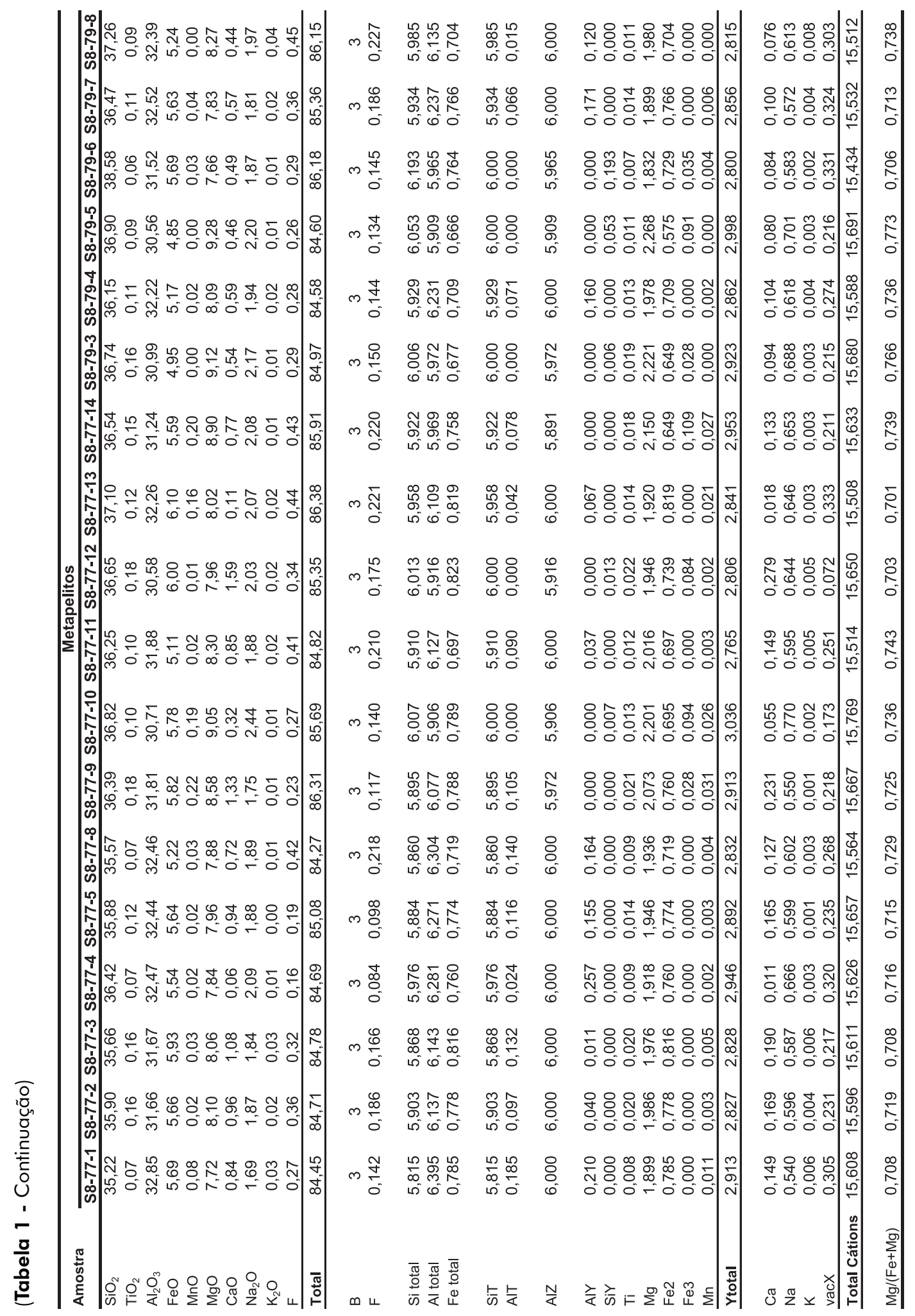




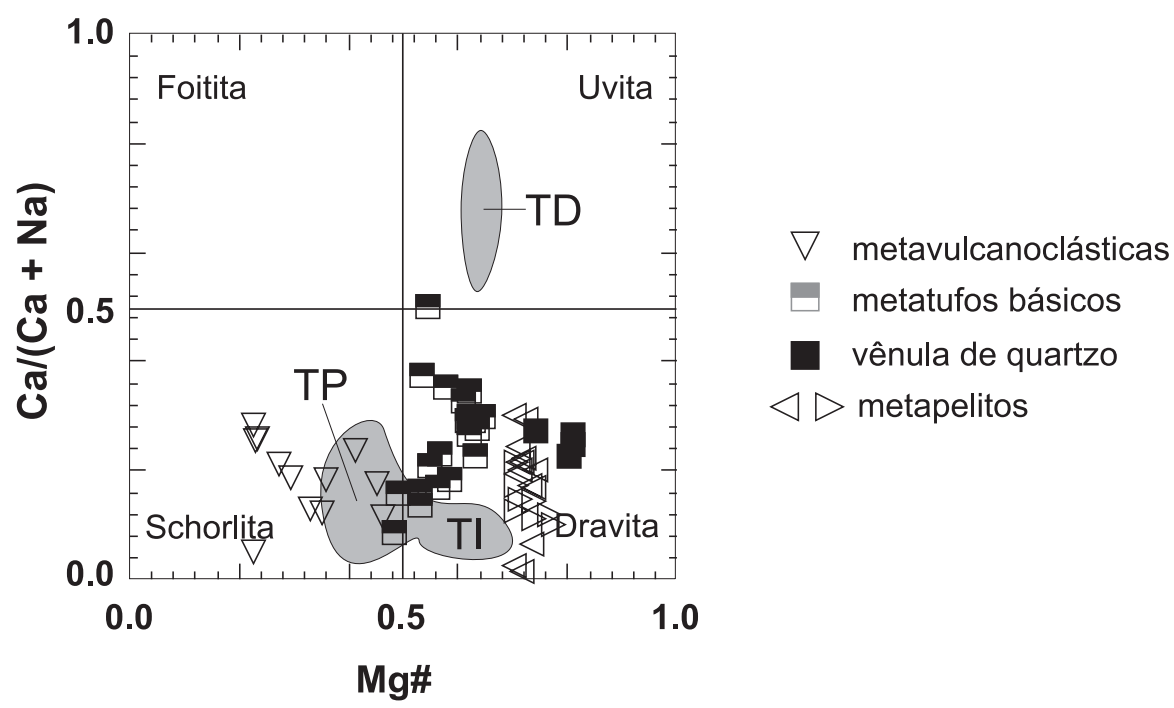

Figura 4. Classificação da turmalina das rochas ricas em turmalina do prospecto Tapera Grande pelo diagrama $\mathrm{Ca} /(\mathrm{Ca}+\mathrm{Na})$ vs. $\mathrm{Mg \#}$. $\mathbf{T P}=$ turmalinitos proximais. $\mathrm{TI}=$ turmalinitos intermediários. $\mathbf{T D}=$ turmalinitos distais ao centro de atividade vulcano-exalativa (Beljavskis et al., 2005).

$\mathrm{Al}$

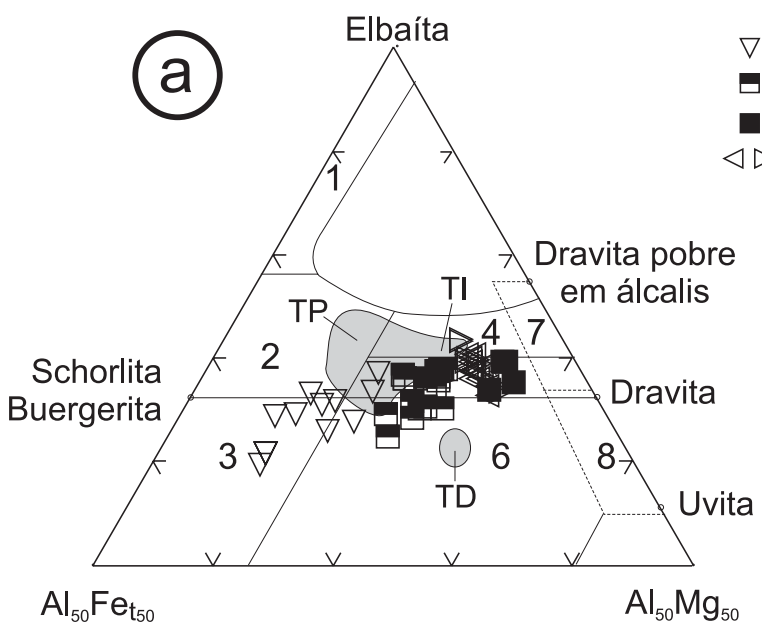

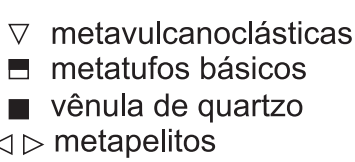

Ca Liddicoatita

\section{tas} \\ (1)
}

Liddicoat

(1)




\section{A turmalina dos metatufos básicos e das metavulcanoclásticas intermediárias a ácidas}

A Figura 6 mostra as principais variações das composições (em apfu) da turmalina dos metatufos básicos e das metavulcanoclásticas intermediárias a ácidas. Retomando a fórmula geral da turmalina, algumas considerações podem ser feitas quanto ao preenchimento das posições $\mathrm{T}$ e $\mathrm{Z}$.

No caso dos metatufos básicos, quando a turmalina apresenta valores de $\mathrm{Mg} \#>0,6$, pode ocorrer a insuficiência em Si para o preenchimento da posição T (Figura 6a). Assim, completada a posição Z (Figura 6c) e havendo excesso de $\mathrm{Al}$, a posição $\mathrm{T}$ é preenchida com o $\mathrm{Al}$ excedente. Quando Mg\# < 0,6, apesar de haver Si suficiente para o preenchimento da posição $\mathrm{T}$ (Figura 6a), pode ocorrer insuficiência de $\mathrm{Al}$ para o preenchimento da posição $\mathrm{Z}$ (Figura 6c), que é, então, completada com Fe, assumido como $\mathrm{Fe}^{3+}$ (Figura 6g). Nessa situação está a turmalina que apresenta $\mathrm{Ti}>0,12$ (Figura 6e), sugerindo que, além de Fe, Ti pode também completar a posição Z. A turmalina do metatufo básico com vênula de quartzo (SRT2-97), por sua vez, praticamente não apresenta insuficiência de Si para o preenchimento da posição $\mathrm{T}$ ou de $\mathrm{Al}$ para o preenchimento da posição $\mathrm{Z}$ e os valores de Ti correspondentes são os mais baixos $(<0,08)$ entre aqueles da turmalina de metatufos básicos (Figura 6e).

A turmalina das metavulcanoclásticas intermediárias a ácidas não apresenta insuficiência de Si para o preenchimento da posição T (Figura 6a). Entretanto, os valores de Al abaixo de 6 são predominantes (Figura 6c), correspondendo a valores elevados de Fe e, em parte, Ti, relativamente à turmalina dos metatufos (Figuras 6e e 6g), indicando a participação de $\mathrm{Fe}$ e possivelmente de Ti no preenchimento da posição $\mathrm{Z}$.

Os valores de $\mathrm{Na}$ são relativamente altos $(>0,7)$ na turmalina das metavulcanoclásticas intermediárias a ácidas e não definem uma tendência em relação a Mg\# (Figura 6i). Por outro lado, os valores de $\mathrm{Ca}$ tendem a diminuir com o aumento de Mg\# (Figura 61), o contrário do que acontece com a turmalina dos metatufos básicos.

A vacância em $X$, tanto na turmalina dos metatufos básicos como na das vulcanoclásticas intermediárias a ácidas, não excede 0,2 (Tabela 1).

\section{A turmalina dos metapelitos}

A insuficiência em Si para preencher a posição Té comum na turmalina dos metapelitos (Figura 6b). Por outro lado, apresenta excesso em Al para o preenchimento da posição $\mathrm{Z}$ (Figura 6d), o que faz com que $\mathrm{Fe}^{3+}$ fique abaixo de 0,1 . Os valores de Ti são muito baixos ( $<0,02$ - Figura 6f). A turmalina de SRT8-77 apresenta valores mais elevados de Fe (em média 0,776 apfu) e mais baixos de Mg (em média 1,997 apfu) relativamente à turmalina de SRT8-79.

Em geral, os valores de Mn estão abaixo de 0,01 apfu, exceto para a turmalina inclusa em granada (Figuras $3 \mathrm{~g}$, 3h e $6 \mathrm{~h})$.

Os valores de $\mathrm{Ca}$ variam entre 0 e 0,3 apfu. Nota-se na Figura $6 \mathrm{~m}$ que boa parte das análises relativas à amostra SRT8-77 tende a apresentar valores de Ca mais elevados do que os da amostra SRT8-79. Os valores de Na também apresentam ampla variação, de 0,5 a 0,8 apfu, havendo uma tendência de serem mais elevados na amostra SRT8-79 (Figura 6j). Conseqüentemente, os valores da vacância em $\mathrm{X}$ variam entre 0,05 a 0,35 .

\section{AMBIENTES DEPOSICIONAIS INDICADOS PELOS TURMALINITOS DA FORMAÇÃO MORRO DA PEDRA PRETA}

Beljavskis et al. (2005) e Beljavskis, Garda e Tassinari (2005) utilizaram as composições químicas da turmalina dos turmalinitos do Grupo Serra do Itaberaba como indicador de ambiente deposicional, caracterizando, dessa forma, os tipos de sistemas hidrotermais operantes e a potencialidade para mineralizações de ouro (Figura 7). Observaram que a turmalina que caracteriza os turmalinitos proximais ao centro vulcano-exalativo, em especial aqueles associados à formação ferrífera e a metachert do prospecto Tapera Grande, têm composições tendendo para o membro extremo schorlita, ao passo que as composições da turmalina dos turmalinitos intermediários a distais tendem ao membro extremo dravita (em Tapera Grande) e uvita (ponto SI-1611 da Figura 1). Nos turmalinitos proximais, a turmalina é mais rica em $\mathrm{Fe}, \mathrm{Na}$ e $\mathrm{Al}$, ao passo que nos intermediários a distais, a turmalina é mais rica em $\mathrm{Mg}$ e $\mathrm{Ca}$. A potencialidade para ouro é indicada pelos turmalinitos proximais e intermediários do prospecto Tapera Grande.

A turmalina das rochas ricas em turmalina deste estudo também mostra tendências semelhantes. A turmalina das metavulcanoclásticas - rochas próximas ao centro exalativo - é mais rica em $\mathrm{Fe}$ e $\mathrm{Na}$ e mais pobre em $\mathrm{Mg}$ e Ca. É interessante notar que os teores de $\mathrm{Al}$ são mais baixos que os dos turmalinitos proximais (Figura 5a). A análise de rocha total da amostra SRT3-112 (Tabela 2) mostra que o teor de $\mathrm{Al}_{2} \mathrm{O}_{3}$ é um pouco mais baixo do que aquele do metatufo básico SRT1-30.

Os metatufos básicos ocupam tanto posições proximais a intermediárias, como posições intermediárias a distais, onde a relação fluido/rocha é menor. O metatufo básico com vênula de quartzo (amostra SRT2-97) enquadra-se na primeira situação: os valores de $\mathrm{Mg \#}$ da turmalina da matriz são 

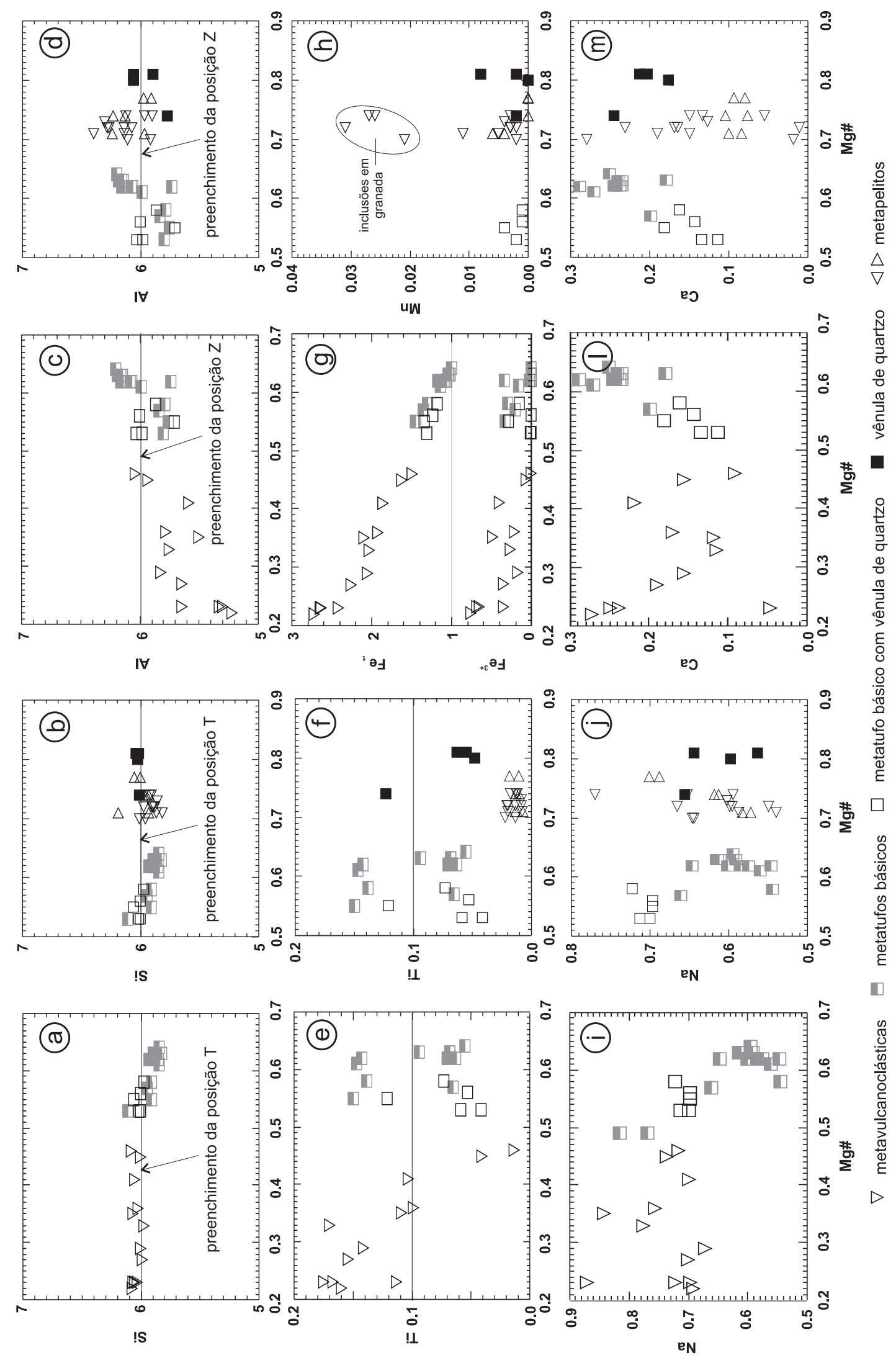

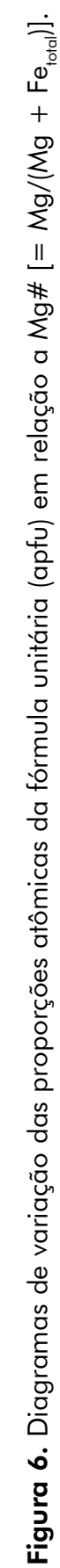




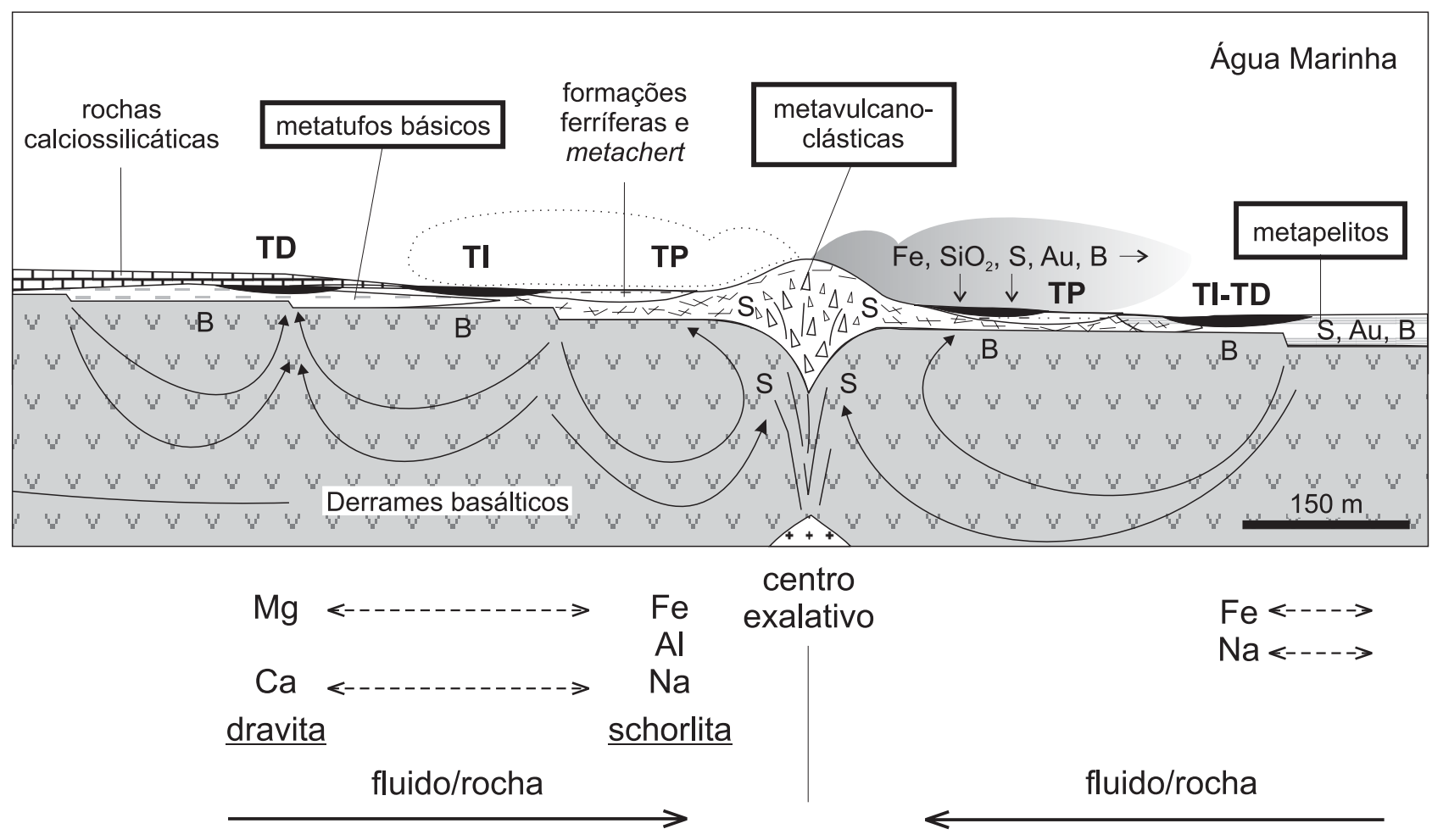

Figura 7. Representação esquemática de um sistema hidrotermal, com a localização dos turmalinitos (TP = proximais; TI = intermediários; TD = distais) e rochas ricas em turmalina em relação ao centro de atividade vulcano-exalativa (mod. de Beljavskis et al., 2005) .

Tabela 2. Análises de rocha total por ICP-MS de algumas rochas ricas em turmalina do Prospecto Tapera Grande (Beljavskis, 2003). Valores em \% em peso.

\begin{tabular}{lcccccccccccc}
\hline Amostra & $\mathbf{S i O}_{2}$ & $\mathrm{TiO}_{2}$ & $\mathbf{A l}_{2} \mathbf{O}_{3}$ & $\mathbf{F e O}_{\mathbf{t}}$ & $\mathbf{M n O}$ & $\mathbf{M g O}$ & $\mathbf{C a O}$ & $\mathbf{N a}_{2} \mathbf{O}$ & $\mathbf{K}_{\mathbf{2}} \mathbf{O}$ & $\mathbf{P}_{2} \mathbf{O}_{5}$ & $\mathbf{C O}_{2}$ & $\mathbf{P F}$ \\
\hline SRT1-30 & 49,25 & 1,47 & 12,27 & 15,77 & 0,30 & 6,37 & 8,72 & 1,44 & 0,68 & 0,05 & 0,17 & 1,25 \\
SRT3-112 & 60,91 & 0,82 & 11,90 & 13,35 & 0,18 & 0,96 & 4,40 & 4,73 & 0,20 & 0,22 & 0,32 & 1,75 \\
SRT8-77 & 61,19 & 0,53 & 15,64 & 5,87 & 0,16 & 5,65 & 2,13 & 3,26 & 1,77 & 0,06 & 0,05 & 2,80 \\
SRT8-79 & 61,29 & 0,60 & 19,13 & 5,93 & 0,10 & 5,67 & 0,77 & 1,67 & 2,75 & 0,08 & 0,02 & 2,19 \\
\hline
\end{tabular}

inferiores a 0,6, sendo mais rica em Fe (Figura 6g) e $\mathrm{Na}$ (Figura 6j) e mais pobre em Ca (Figura $6 \mathrm{~m}$ ) do que a turmalina dos demais metatufos. A turmalina da vênula de quartzo contém Si (Figura 6b), Al (Figura 6d) e Ti (Figura 6f) em valores de apfu semelhantes aos daquela do metatufo SRT2-97. Os valores de Na (Figura 6j) e Ca (Figura 6m), entretanto, variam dentro dos intervalos de valores de $\mathrm{Na}$ e Ca correspondentes à turmalina dos metatufos de características intermediárias a distais. A turmalina da vênula de quartzo é muito pobre em $\mathrm{Fe}\left(3,72 \%<\mathrm{FeO}_{\mathrm{t}}<5,43 \%\right)$ e rica em $\mathrm{MgO}(8,76 \%<\mathrm{MgO}<9,74 \%)$, resultando nos elevados valores de $\mathrm{Mg \#}$ (ca. 0,8).
As análises de rocha total (Tabela 2) mostram que há diferenças na composição dos metapelitos SRT8-77 e SRT8-79, em especial em relação ao $\mathrm{Al}_{2} \mathrm{O}_{3}(15,64 \%$ e $19,13 \%) ; \mathrm{MnO}(0,16 \%$ e $0,10 \%) ; \mathrm{CaO}(2,13 \%$ e $0,77 \%)$; $\mathrm{Na}_{2} \mathrm{O}(3,26$ e $1,67 \%)$ e $\mathrm{K}_{2} \mathrm{O}(1,77$ e $2,75 \%)$. Os teores mais elevados de $\mathrm{Al}_{2} \mathrm{O}_{3}$ e $\mathrm{K}_{2} \mathrm{O}$ em SRT8-79 refletem a presença de estaurolita e a maior quantidade de biotita nessa amostra em relação à SRT8-77. Por outro lado, o teor mais elevado de $\mathrm{MnO}$ de SRT8-77 reflete a presença de granada com $\mathrm{Mn}\left[\mathrm{Fe}_{1,6} \mathrm{Mg}_{0,5} \mathrm{Mn}_{0,7} \mathrm{Ca}_{0,2}\left(\mathrm{Al}_{1,9} \mathrm{Fe}_{0,1}\right)_{2} \mathrm{Si}_{3} \mathrm{O}_{12}\right]$.

Em relação às composições da turmalina, o que chama a atenção são os valores em apfu mais elevados de Ca na amostra 
SRT8-77, em relação à SRT8-79 (Figura 6m). Para os demais elementos, há praticamente uma superposição dos intervalos de valores desses elementos para a turmalina dos metapelitos.

Uma vez que as composições da turmalina dos metapelitos estão próximas àquelas dos turmalinitos intermediários (Figuras 4 e 5), os metapelitos foram posicionados próximos aos turmalinitos intermediáriosdistais da Figura 7. Como sugerem os diagramas de Henry e Guidotti (Figura 5), a fonte de Al para a geração da turmalina dos metapelitos e dos turmalinitos associados é o próprio metapelito aluminoso. A rocha pode também ter sido fonte de $\mathrm{Mg}$, uma vez que apresenta teores de $\mathrm{MgO}$ relativamente elevados (Tabela 2), e de boro. Assim, as composições da turmalina dos metapelitos representam mais a composição da própria rocha hospedeira, do que propriamente a do fluido hidrotermal.

Os metapelitos provenientes do furo de sondagem SRT8 localizam-se próximos ao grafita xisto amostrado pelo furo de sondagem SRT11 (Figura 2). Beljavskis, Garda e Sayeg (1999) localizaram em seção polida dessa rocha, por imagens de elétrons retroespalhados, partículas de ouro tido como singenético, uma vez que a rocha também contém sulfetos do Estágio I, sin-sedimentares, conforme Garda et al. (2002). Beljavskis (2003) obteve teores de ouro relativamente elevados para a amostra SRT8-77, o que pode indicar a capacidade desses fluidos de remobilizar ouro, além de $\mathrm{Fe}, \mathrm{Mg}, \mathrm{Ca}$ e $\mathrm{Na}$.

Estudos de inclusões fluidas em metachert associado aos turmalinitos proximais do prospecto Tapera Grande indicaram que a composição dos fluidos é aquo-carbônica e de baixa salinidade (Beljavskis, 2003). Os raros cristais de halita encontrados em algumas inclusões fluidas em metachert e os dados de isótopos estáveis obtidos para turmalina de turmalinito proximal-intermediário $\left(\delta^{18}\right.$ O: 12,9 a 13,5\%o e $\delta$ D: -104 a -103\% ; Garda et al., 2003), apontando para uma origem sedimentar, mostram que os fluidos analisados por microtermometria resultaram da mistura de fluidos salinos e águas conatas. A competência desses fluidos para mobilizar metais deve ter sido relativamente baixa, pois o ouro encontra-se tipicamente disseminado ou remobilizado nas rochas hospedeiras e não concentrado, por exemplo, em veios de quartzo.

A origem desses fluidos deve ter sido hidrotermalmetamórfica, uma vez que a turmalina da SRT8-77 ocorre não só disseminada no metapelito, mas também inclusa em granada.

\section{CONSIDERAÇÕES FINAIS}

O estudo comparativo entre as composições da turmalina dos turmalinitos e das rochas ricas em turmalina de Tapera Grande mostrou que as condições para a formação desse mineral foram muito semelhantes.
No caso das rochas ricas em turmalina, os fluidos de origem hidrotermal-metamórfica promoveram a redistribuição de ouro e proporcionaram boro para a geração de turmalina que apresenta as características da rocha hospedeira, mais do que propriamente as características do fluido, o que mostra que a razão fluido/rocha também foi baixa em porções mais proximais do centro exalativo.

A composição desses fluidos primários (aquo-carbônica e de baixa salinidade), que remobilizaram ouro sin-sedimentar ou singenético, não foi favorável à formação de depósitos de sulfetos maciços (Beljavskis, 2003).

Ressalta-se, no entanto, que situação diferente ocorreu durante o Neoproterozóico, quando não somente ouro, mas também sulfetos foram remobilizados por fluidos relacionados aos eventos de cisalhamento que afetaram o Grupo Serra do Itaberaba (Garda et al., 2003; Beljavskis, 2003).

\section{IN MEMORIAM}

Este trabalho reúne as duas comunicações orais apresentadas no X Congresso Brasileiro de Geoquímica e II Simpósio de Geoquímica dos Países do Mercosul (Garda, Beljavskis e Mansueto, 2005; Beljavskis, Garda, Tassinari, 2005). Assim como as apresentações, este trabalho é dedicado à memória de Charles V. Guidotti, falecido em 19/05/2005.

\section{REFERÊNCIAS BIBLIOGRÁFICAS}

BELJAVSKIS, P. Caracterização das mineralizações e os ambientes deposicionais dos sulfetos, turmalinas e ouro no contexto da Formação Morro da Pedra Preta do Grupo Serra do Itaberaba, SP. 2003. 158 p. Tese (Doutorado) Instituto de Geociências, Universidade de São Paulo, São Paulo, 2003.

BELJAVSKIS, P. Prospecção geoquímica experimental na ocorrência de ouro Tapera Grande - Guarulhos (SP). 1988. 161 p. Dissertação (Mestrado) - Escola Politécnica, Universidade de São Paulo, São Paulo, 1988.

BELJAVSKIS, P.; GARDA, G. M.; TASSINARI, C. C. G. Turmalinitos e as mineralizações de ouro e sulfetos na sequiência vulcanossedimentar mesoproterozóica do Grupo Serra do Itaberaba-SP(Brasil). In: CONGRESSOBRASILEIRO DE GEOQUÍMICA, 10., 2005, Porto de Galinhas. Anais... [S.l.]: SBG, 2005. 1 CD-ROM. Resumo 12-505.pdf.

BELJAVSKIS, P.; GARDA, G M.; MANSUETO, M. S.; SILVA, D. Turmalinitos vulcanogênicos da Formação Morro da Pedra Preta do Grupo Serra do Itaberaba (SP): petrografia, composição química da turmalina e implicações metalogenéticas. Geologia USP. Série Científica, v. 5, p.1-18, 2005. 
BELJAVSKIS, P.; GARDA, G. M.; SAYEG, I. J. Application of SEM in the study of gold mineralizations in the Morro da Pedra Preta Formation, Grupo Serra do Itaberaba - São Paulo, Brazil. Acta Microscópica, v. 8, (Supplement A), p. 125-126, 1999.

FONSECA-ZANG, W. A.; ZANG, J. W.; HOFMEISTER, W. Characterization of ferric iron tourmaline from Germany. In: REUNIÃO ANUAL DA SBPC, 54., 2002, Goiânia. [Anais/ resumos...]. Disponível em: <http://www.quimicaindustrial.com/ferric_iron_tourmaline.html $>$. Acesso em: 3 fev. 2006.

GARDA, G. M.; BELJAVSKIS, P.; MANSUETO, M. S. Rochas ricas em turmalina da Formação Morro da Pedra Preta: Relações com os turmalinitos portadores de ouro do Grupo Serra do Itaberaba, SP. In: CONGRESSO BRASILEIRO DE GEOQUÍMICA, 10, 2005, Porto de Galinhas. Anais... [S.1.]: SBG, 2005. 1 CD-ROM. Resumo 12-501.pdf.

GARDA, G. M.; BELJAVSKIS, P.; JULIANI, C; SILVA, D. Geochemistry of tourmalines associated with iron formation and quartz veins of the Morro da Pedra Preta Formation, Serra do Itaberaba Group (São Paulo, Brazil). Anais da Academia Brasileira de Ciências, v. 75, p. 209-234, 2003.

GARDA, G. M.; BELJAVSKIS, P.; JULIANI, C.; BOYCE, A. J. Sulfur stable isotope signatures of the Morro da Pedra Preta Formation, Serra do Itaberaba Group, Sao São Paulo State, Brazil. Geochimica Brasiliensis, v. 16, p. 79-97, 2002.

HENRY, D. J.; GUIDOTTI, C. V. Tourmaline as a petrogenetic indicator mineral: an example from the staurolite-grade metapelites of NW Maine. American Mineralogist, v. 70, p. 1-15, 1985.

JULIANI, C. Geologia, petrogênese e aspectos metalogenéticos dos grupos Serra do Itaberaba e São Roque na região das serras do Itaberaba e da Pedra Branca, NE da cidade de São Paulo, SP. 1993. 2 v. Tese (Doutorado) - Instituto de Geociências, Universidade de São Paulo, São Paulo, 1993.

JULIANI, C.; HACKSPACHER, P. C.; DANTAS, E. L.; FETTER, A. H. The Mesoproterozoic volcano-sedimentary Serra do Itaberaba Group of the central Ribeira Belt, São Paulo State, Brazil: implication for the age of overlying São Roque Group. Revista Brasileira de Geociências, v. 30, p. 82-86, 2000.

JULIANI, C.; PÉREZ-AGUILAR, A.; MARTIN, M. A. B. Geotermobarometria e evolução metamórfica P-T-d do Grupo Serra do Itaberaba (SP). Anais da Academia Brasileira de
Ciências, v. 69, p. 441-442, 1997.

JULIANI, C.; BELJAVSKIS, P. Revisão da litoestratigrafia da faixa São Roque/Serra do Itaberaba (SP). Revista do Instituto Geológico, v. 16, p. 33-58, 1995.

PLIMER, I .R. Tourmalines associated with Australian Proterozoic submarine exhalative ores. In: FRIEDRICH G. H.; HERZIG, P. M. Base metal sulfide deposits in sedimentary and volcanic environments. Berlin: Springer-Verlag, 1988. p. 255-283.

PLIMER, I.R. The association of tourmaline with stratiform scheelite deposits. Mineral Deposita, v. 22, p. 282-291, 1987.

PLIMER, I. R. Tourmalinites from the Golden Dyke Dome, Northern Australia. Mineral Deposita, v. 21, p. 263-270, 1986.

PLIMER, I. R. The association of tourmaline-bearing rocks with mineralization at Broken Hill, N.S.W. In: ANNUAL AUSTRALIAN INSTITUTION OF MINING AND METALLURGY CONFERENCE, 7., 1983. Proceedings... [S.l: s.n.], 1983. p. 157-176.

SLACK, J. F. Tourmaline associations with hydrothermal ore deposits. In: Boron: mineralogy, petrology and geochemistry. Reviews in Mineralogy, v. 33, p. 559-643, 1996.

SLACK J. F. Tourmaline in Appalachian-Caledonian massive sulphide deposits and its exploration significance. Transactions of the Institution of Mining and Metallurgy, v. 91, p. B81-B89, 1982.

SLACK, J. F.; HERRIMAN, N.; BARNES, R.G.; PLIMER, I. R. Stratiform tourmalines in metamorphic terranes and their geologic significance. Geology, v. 12, p. 713-716, 1984.

TAYLOR, B. E.; SLACK, J. F. Tourmalines from the Appalachian-Caledonian massive sulfide deposits: textural, chemical, an isotopic relationships. Economic Geology, v. 79, p. 1703-1726. 1984.

WILLNER, A. P. Tourmalines from the stratiform peraluminous metamorphic suite of the Central Namaqua Mobile Belt (South Africa). Mineral Deposita, v. 27, p. 304-313, 1992.

YAVUZ, F. TOURMAL: Software package for tourmaline, tourmaline-rich rocks and related ore deposits. Computers \& Geosciences, v. 23, p. 947-959, 1997. 